The $8^{\text {th }}$ International Conference of the Slovenian Society for Non-Destructive Testing

"Application of Contemporary Non-Destructive Testing in Engineering"

September 1-3, 2005, Portorož, Slovenia, pp. 265-275

\title{
COMPARATIVE MEASUREMENT OF RESIDUAL STRESSES WITH THE METHOD BASED ON THE MAGNETIC BARKHAUSEN NOISE AND THE RELAXATION METHOD
}

\author{
P. Žerovnik, J. Grum \\ University of Ljubljana, Faculty of Mechanical Engineering, \\ Aškerčeva 6, 1000 Ljubljana, Slovenia, \\ E-mails: pavle.zerovnik@fs.uni-lj.si, janez.grum@fs.uni-lj.si
}

\begin{abstract}
For an efficient prediction of residual stresses in a material or a machine part the nondestructive method based on the magnetic Barkhausen noise is, among others, employed in practice. An experimental system developed at home and including measuring and assessment units has proved to be very efficient in various applications of surface hardening or cold hardening, and heat treatment. The present paper treats measurements of residual stresses obtained using the standard relaxation method based on a continuous electrochemical removal and with measurement of deformations with resistance measuring bands in comparison to the determination of residual stresses with the magnetic method based on the Barkhausen noise. A comparative analysis of the results obtained was carried out with flat specimens made of heattreatment structural steel C45E that was, after oil quenching, additionally high-tempered. The residual stresses in a thin surface layer of differently heat-treated and ground specimens were determined using the two methods.
\end{abstract}

Keywords: Magnetic Barkhausen noise, Electrochemical removal, Heat treatment, Residual stresses

\section{Introduction}

The non-destructive magnetic method based on the Barkhausen noise has been increasingly applied to on-line monitoring of the state of a material during processing, as well as of parts during their operation. The method is sufficiently reliable, fast and repeatable. With adequate software for processing and analysis of the signals processed it permits efficient determination of microstructure, hardness, and residual stresses as features for the description of surface integrity. For the methods mentioned the authors present different techniques of measuring residual stresses.

Degner and Lauterlein [1] presented their own experimental system for capturing voltage signal of the magnetic BN and showed the way of evaluating it. From the captured voltage signal they determined calibration curve for determining of material-hardness and residual stress profiles. Residual stresses were determined on the basis of an average intensity of the voltage signal with regard to longitudinal and transverse magnetisation of the specimen or machine part respectively. 
Yamada and co-authors [2] tested a magnetic-anisotropy sensor for capturing the induced voltage with different sensor arrangements on the specimen subjected to tensile and compressive loads. Similar studies were accomplished by Langman [3], who arranged three coils inside a magnetising yoke, the one in the middle being rotating and designed for capturing the maximum voltage signal. Studies of stress states were accomplished on the specimens with a uniaxial tensile load and a biaxial tensile load. He indicated the value of the output voltage at the calibration curves.

Langman [3] tested the selected experimental technique and assessment of the results with the calibration curves on a loaded disc of soft steel. He compared the experimental results of stress measurements with the theoretically calculated values obtained with a uniaxially loaded disc in the longitudinal direction and found an extremely good agreement of the results.

Theiner and Deimel [4] investigated variations in hardnesses and residual stresses on a flat specimen and on a welded pipe by means of a 3MA analyser and a corresponding micro magnetic sensor. Hardnesses and residual stresses were determined indirectly with the maximum amplitude value of the voltage signal and coercitive intensity of the magnetic field. Taking into account that Barkhausen events were registered with a frequency of $100 \mathrm{kHz}$ it may be stated that an average interaction depth is shorter than $100 \mu \mathrm{m}$ and that the agreement of the results obtained with both methods is very good.

Theiner and Altpeter [5] presented various micro magnetic techniques, an experimental prototype device, and numerous results. A technique of the device calibration by means of the maximum amplitude voltage and intensity of the magnetic field with regard to the mechanical stress state in a ferromagnetic material is shown. Determination of residual stress profile with the micro magnetic method from the maximum amplitude voltage was compared with the $\mathrm{X}$ - ray difraction method. It turned out that the method proposed was good because it showed the nature of residual stresses (tension/compression) and the depth of their transition whereas the differences in determination of maximum tensile or compressive stresses through the thickness of a specimen or a machine part were considerable, i.e., up to $30 \%$.

Desvaux and Gualandri [6] developed software for estimating the residual stress profiles on the bearing contact zone after grinding and prestressing or after operation conditions.

Grum and Žerovnik [7] showed that the micromagnetic method is very efficient in assessing the state of material under different shot penning conditions including the prediction of the microhardness profiles and residual stress profiles in the thin shot penned surface layer.

\section{Experimental procedure}

The frequently employed heat-treatment structural steel C45E was used. This steel is suitable for production of structural parts subjected to medium loads during their operation. The basic steel properties are good workability in the soft-annealed state and simple and efficient heat treatment. After heat treatment the steel concerned shows strength in the medium range and considerable toughness, which indicates a weak tendency to crack formation. The steel manufacturer warns that with deficient structural parts and unsuitably surface-hardened layers considerable notch effects may occur. They may result in breaking of the material.

The residual stresses were determined by the application of both the destructive relaxation method and the micro-magnetic method to flat specimens with $150 \times 40$ in size and a thickness of $9 \mathrm{~mm}$. With each method testing was repeated five times and three different heat treatments were applied.

The specimens were prepared as follows:

- Oil quenching from a temperature of austenitization $T_{\mathrm{A}}$ of $860{ }^{\circ} \mathrm{C}$ and high-tempering at three different temperatures, i.e. $T_{\mathrm{t} 1}=220{ }^{\circ} \mathrm{C}, T_{\mathrm{t} 2}=460{ }^{\circ} \mathrm{C}, T_{\mathrm{t} 3}=700{ }^{\circ} \mathrm{C}$. 
Different high-tempering temperatures after quenching were chosen to cause the formation of different microstructures and microhardnesses of the specimens. Increasing of high-tempering temperature will reduce specimen hardness and residual stresses.

After hardening of $\mathrm{C} 45 \mathrm{E}$, the microstructure of tetragonal martensite transforming with lower high-tempering temperatures $\left(220^{\circ} \mathrm{C}\right)$ into cubic or so-called tempered martensite is obtained. With higher high-tempering temperatures $\left(460^{\circ} \mathrm{C}\right)$ martensite will disintegrate into a bainitic microstructure, and with the highest tempering temperatures $\left(700^{\circ} \mathrm{C}\right)$ fine pearlite will form. The difference between the microstructure of bainite and that of fine pearlite consists in the size and distribution density of cementite in ferrite after soft annealing. Thus in fine bainite there are very fine feathers of cementite in the ferritic matrix whereas in fine pearlite there is coagulated fine pearlitic cementite in the ferritic matrix. The size and density of coagulated cementite in the ferrite matrix determine steel hardness after heat treatment.

After heat treatment plane-surface grinding with the following grinding parameters was carried out additionally:

- grinding depth

- $\quad$ cutting speed of the grinding wheel

- velocity of specimen movement

- $\quad$ type of grinding wheel

$$
\begin{aligned}
& a_{\mathrm{p}}=0.05 \mathrm{~mm} \\
& v_{\mathrm{c}}=20 \mathrm{~m} / \mathrm{s} \\
& v_{\mathrm{w}}=400 \mathrm{~mm} / \mathrm{s} \\
& 2 \mathrm{~B} 60 \mathrm{~L} 8 \mathrm{~V}
\end{aligned}
$$

Figure 1 shows a flow chart of operations in the preparation of the specimens whereas in Table 1 the number of repetitions is given.

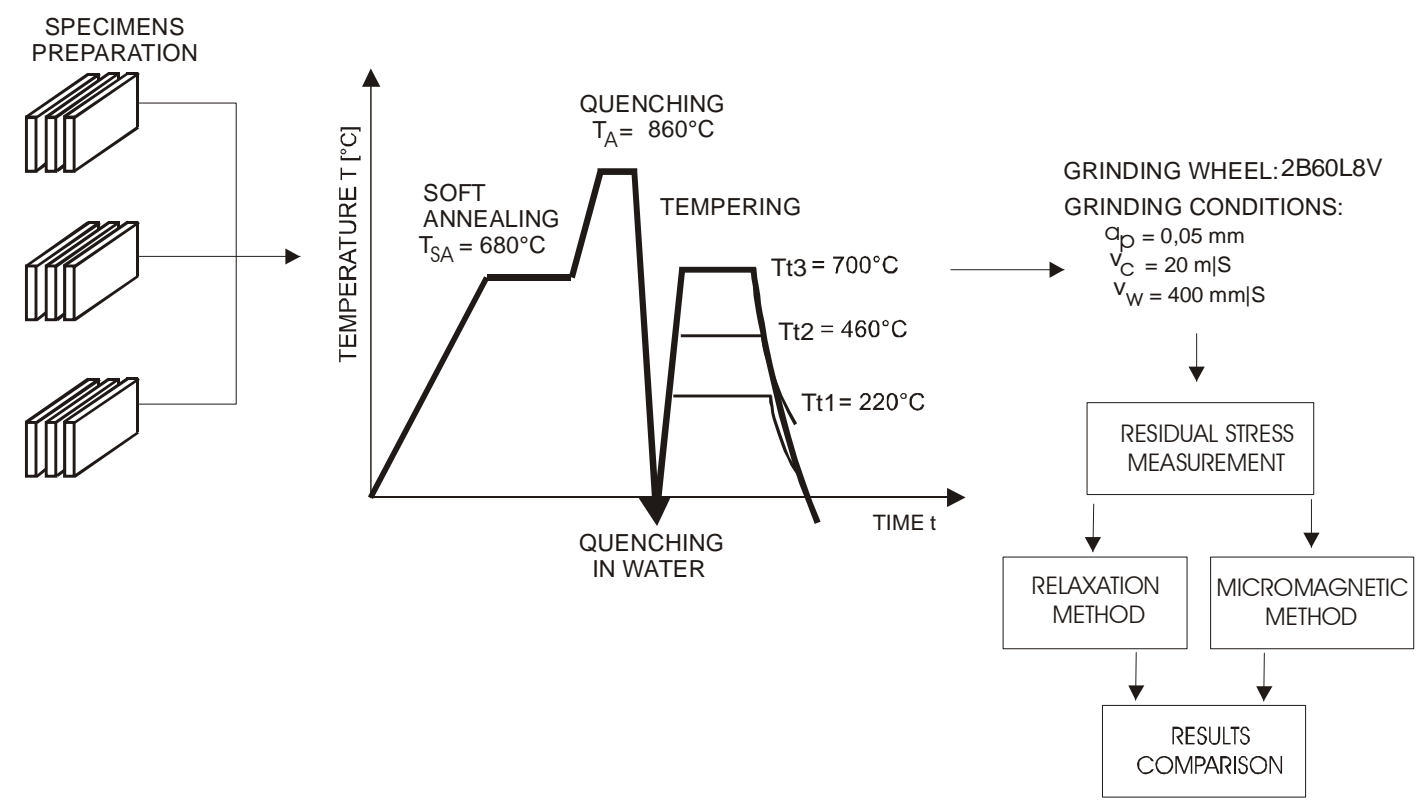

\begin{tabular}{|c|c|c|c|}
\hline $\begin{array}{c}\text { QUENCHING AND } \\
\text { TEMPERING } \\
\text { CONDITIONS }\end{array}$ & $\begin{array}{c}\text { GRINDING } \\
\text { CONDITIONS }\end{array}$ & $\begin{array}{l}\text { RELAXATION } \\
\text { METHOD } \\
\text { (N. SPECIMENS) }\end{array}$ & $\begin{array}{c}\text { MICROMAGNETIC } \\
\text { METHOD } \\
\text { (N. SPECIMENS) }\end{array}$ \\
\hline $\begin{aligned} \mathrm{T}_{\mathrm{A}} & =860^{\circ} \mathrm{C} \\
\mathrm{T}_{\mathrm{t} 1} & =220^{\circ} \mathrm{C}\end{aligned}$ & \multirow{3}{*}{$\begin{array}{c}\mathrm{a}_{\mathrm{p}}=0,05 \mathrm{~mm} \\
\mathrm{v}_{\mathrm{c}}=20 \mathrm{~m} / \mathrm{s} \\
\mathrm{v}_{\mathrm{w}}=400 \mathrm{~mm} / \mathrm{s} \\
\text { WHEEL: } 2 \mathrm{~B} 60 \mathrm{~L} 8 \mathrm{~V}\end{array}$} & $5 X$ & $5 X$ \\
\hline $\begin{aligned} \mathrm{T}_{\mathrm{A}} & =860^{\circ} \mathrm{C} \\
\mathrm{T}_{\mathrm{t} 2} & =460^{\circ} \mathrm{C}\end{aligned}$ & & $5 X$ & $5 \mathrm{X}$ \\
\hline $\begin{aligned} \mathrm{T}_{\mathrm{A}} & =860^{\circ} \mathrm{C} \\
\mathrm{T}_{\mathrm{t} 3} & =700^{\circ} \mathrm{C}\end{aligned}$ & & $5 X$ & $5 \mathrm{X}$ \\
\hline
\end{tabular}

Fig. 1: Flow chart of operations prior to measurement of residual stresses.

Table 1: The number of repetitions of individual heat-treatment regimes and plane-surface grinding. 


\section{The manner of measurement of residual stresses}

\subsection{Determination of residual stresses with the relaxation method}

Figure 2 shows how the residual stresses are determined with the relaxation method using electrochemical dissolution of a stressed layer. Relaxation is deformation of a specimen measured with a resistance measuring band. The removed thickness of the stressed layer can be determined with the measurement of the initial thickness or with the determination of the total depth of the layer removed. It is characteristic of both ways of measurement of the depth of the layer removed that the process of dissolution of the specimen in an electrolyte; therefore, in the first phase testing of material removal should be performed. For the determination of the thickness of the layer removed a calibration curve of electrochemical dissolution indicating the thickness $z_{\mathrm{i}}$ removed in time $t_{\mathrm{i}}$ was used. This means that by measuring the time the thickness of the layer removed $\Delta z$ can be determined by means of the calibration curve. The rate of dissolution depends on the voltage of the electrolyte used, current density at the specimen surface, and the distance between the anode and cathode. In our case the dissolution conditions were the following:

- distance between the anode and cathode $\delta=10 \mathrm{~mm}$,

- current density at the specimen surface $D_{\mathrm{a}}=0.5 \mathrm{~A} / \mathrm{cm}^{2}$,

- voltage in the electrolyte $U=8 \mathrm{~V}$,

- the rate of material dissolution $v_{\mathrm{e}}=0.01 \mathrm{~mm} / \mathrm{min}$, and

- the electrolyte is $5 \%$ solution of $\mathrm{NaCl}$

Deformations may be measured with a contact or without it. In our case the resistance-measuring band was chosen. It was mounted at the opposite side of the specimen, which means the opposite side of electrochemical dissolution as well.

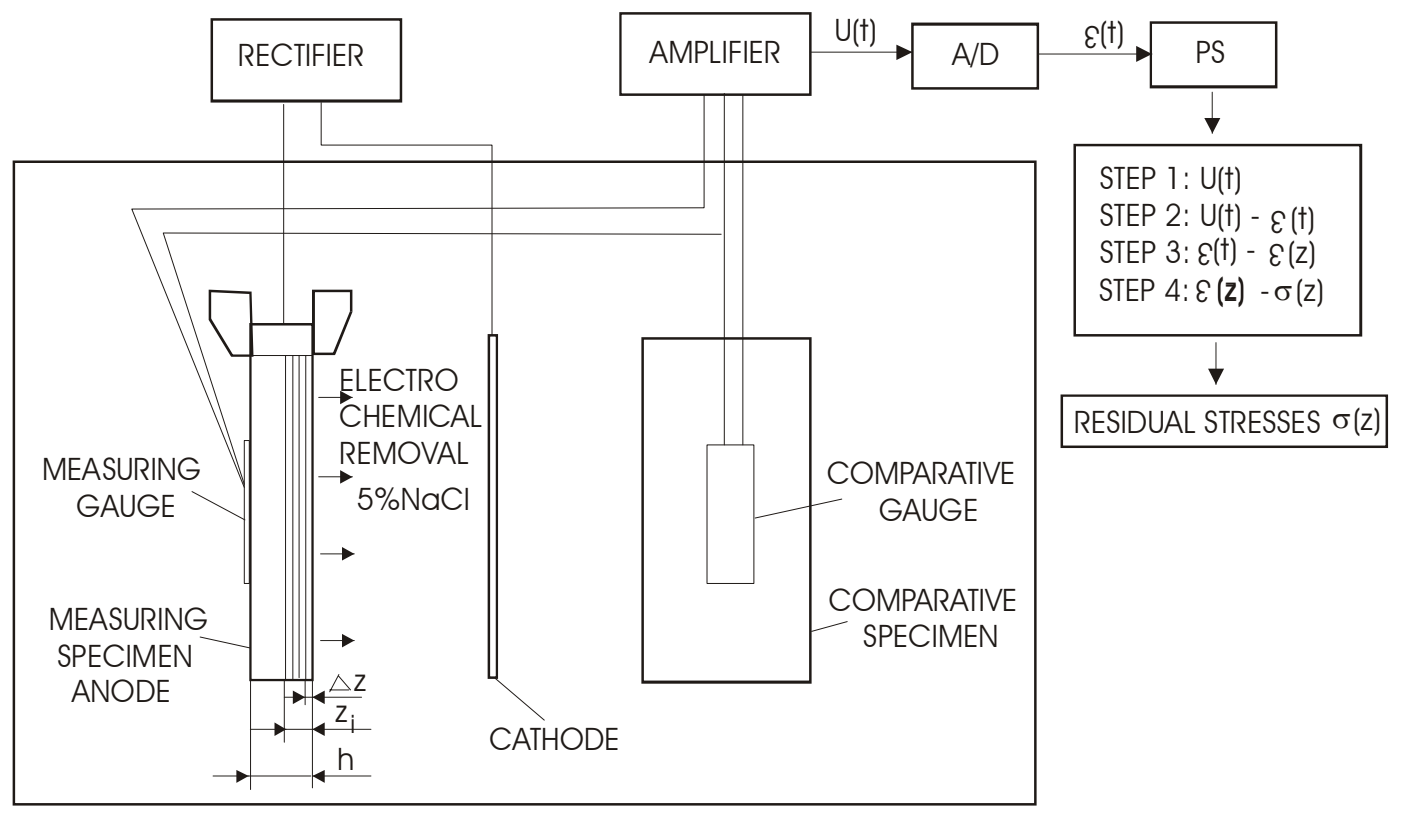

Fig. 2: Schematic representation of determination of residual stresses using relaxation method.

\subsection{Determination of residual stresses with the micro-magnetic method}

Figure 3 shows an experimental setup for magnetizing specimens and capturing the voltage induced in a measuring coil. The magnetizing unit consists of a signal generator, a current-power amplifier, and magnetizing yoke. The unit for capturing induced-voltage signals from the measuring coil consists of a signal amplifier, and a band-pass filter. The measuring coil is designed to detect changes of the magnetic flux density $B$, which, in turn, represents movements 
of magnetic-domain walls. The last module of the experimental setup consists of a computeraided unit for signal processing and statistical data processing.

In testing of materials with the experimental setup chosen, a magnetic field required to produce movement of the magnetic-domain walls is generated. During magnetisation the magnetic domains are slowly turning in the direction of the outer magnetic field and are increasing due to a rapid increase in the magnetic flux density $B$. Changes of the magnetic flux density will induce voltage impulses in the measuring coil of a sensor that are treated as the magnetic Barkhausen noise.

Before starting the experimental procedure optimum magnetizing parameters should be determined. The choice of the magnetising parameters depended mainly on the number of outbursts in the voltage signal. The experimental work performed by now has shown that voltage signals with a greater density of voltage outbursts provide a larger number of useful data on the material.

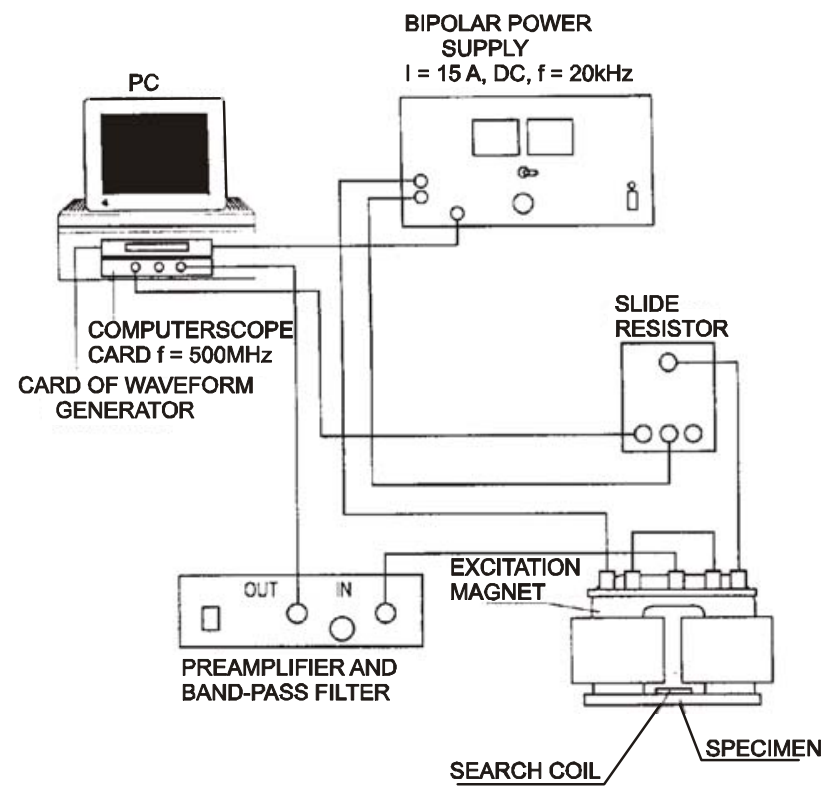

Fig. 3: Experimental setup for determination of residual-stress profile with micro-magnetic method.

\subsection{Processing of the voltage signals captured}

The first research phase was focused on the assessment of reliability of the measurement performed with the micro-magnetic method based on capturing the voltage induced during the magnetisation process. Experimental measurements using the experimental setup showed that relatively small differences among the individual parameters of the surface integrity could be detected efficiently.

The voltage signals captured cannot be directly related to the different parameters of surface integrity. A signal analysis is carried out with the processing method chosen, then a statistical method is used to determine the relation between the micro-magnetic change detected and the parameter of surface integrity chosen. Statistical tests of mean value and signal variance confirmed the repeatability of the results obtained, and the correlation coefficients calculated showed that the power signal, i.e. variance of the voltage signal after processing, is a good estimator for the description of the state of a ferromagnetic material. A power frequency spectrum with the calculation of the variance of the voltage signals was thus used to determine the residual stresses after heat treatment and plane-surface grinding.

The determination of the residual stresses was carried out on the heat-treated specimens, and then on the specimens that were, after heat treatment, also plane-surface ground. The procedure 
of determination of the residual stresses is based on calibration curves. The latter further permit the determination of residual stresses in unknown specimens.

The determination of the unknown residual stresses is shown in Fig. 4. Processing of the voltage signals captured depends on the band-pass Butterworth filter, which lets the signal captured pass in different frequency ranges. In our case the individual signal variances may be treated in a frequency range from 1 to $200 \mathrm{kHz}$. A suitable computer programme shall be used to determine the variance of the voltage signal captured at the analysing frequency chosen.

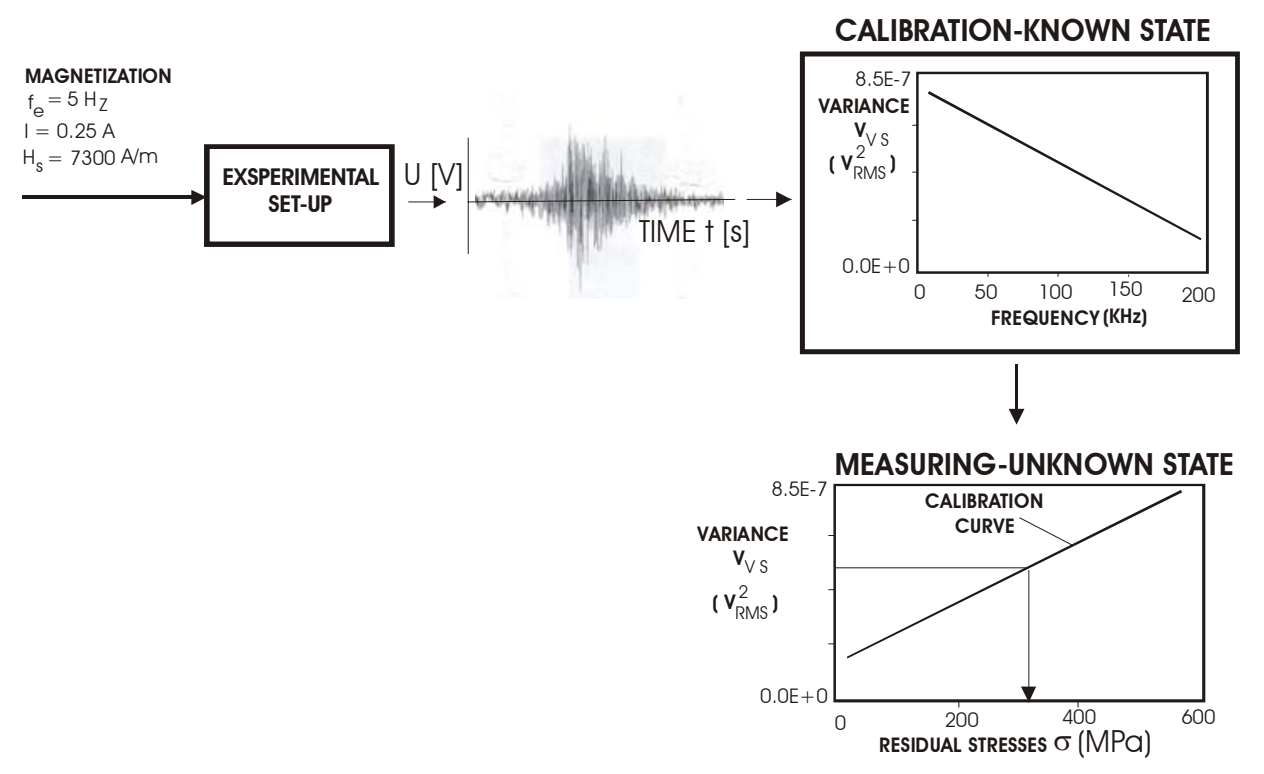

Fig. 4: Determination of residual stresses by means of calibration curves.

Table 2: Micro-magnetic characteristics of signal processing.

\begin{tabular}{|c|c|c|}
\hline $\begin{array}{l}\text { HARDENED AND } \\
\text { TEMPERED } \\
\text { CONDITIONS } \\
\end{array}$ & $\begin{array}{l}\text { BARKHAUSEN } \\
\text { NOISE SIGNAL }\end{array}$ & $\begin{array}{l}\text { VALUE AFTER SIGNAL } \\
\text { PROCESSING }\end{array}$ \\
\hline $\begin{aligned} \mathrm{T}_{\mathrm{A}} & =860^{\circ} \mathrm{C} \\
\mathrm{T}_{\mathrm{t} 1} & =220^{\circ} \mathrm{C}\end{aligned}$ & TIME † [s] & $\begin{array}{l}V_{V S}=22,4\left[V_{R M S}^{2}\right] \\
G(f)=8 \times 10^{-3}\left[V^{2} \backslash \mathrm{Hz}\right] \\
\Delta t=10,3[\mathrm{~ms}]\end{array}$ \\
\hline $\begin{array}{l}\mathrm{T}_{\mathrm{A}}=860^{\circ} \mathrm{C} \\
\mathrm{T}_{\mathrm{t} 2}=460^{\circ} \mathrm{C}\end{array}$ & TIME † [s] & $\begin{array}{l}V_{V s}=136,1\left[\mathrm{~V}_{\mathrm{RMS}}^{2}\right] \\
\mathrm{G}(\mathrm{f})=6 \times 10^{-5}\left[\mathrm{~V}^{2} \mathrm{~Hz}\right] \\
\Delta t=5,1[\mathrm{~ms}]\end{array}$ \\
\hline $\begin{array}{l}\mathrm{T}_{\mathrm{A}}=860^{\circ} \mathrm{C} \\
\mathrm{T}_{\mathrm{t} 3}=700^{\circ} \mathrm{C}\end{array}$ & TIME † [s] & $\begin{array}{l}V_{V S}=241,8\left[V_{\text {RMS }}^{2}\right] \\
G(f)=4 \times 10^{-6}\left[V^{2} \backslash \mathrm{Hz}\right] \\
\triangle t=2,6[\mathrm{~ms}]\end{array}$ \\
\hline
\end{tabular}

In addition to the variance of voltage signals, signal processing can be used to determine other micro-magnetic characteristics that provide good statistical relations with the parameter of surface integrity searched for. Table 2 gives comparative values of the characteristics chosen of the voltage signal, i.e.:

- $\quad$ variance of the entire voltage signal, $V_{\mathrm{VS}}$

- $\quad$ spectrum power at the frequency chosen, $G(f)$, and

- time delay of the signal from the sinusoid of the magnetizing current, $\Delta t$. 
The depth of sensing is calculated using the following equation $[8,9]$ and depends on the following parameters:

$$
\delta=\sqrt{\frac{1}{\pi \cdot f_{\mathrm{a}} \cdot \sigma \cdot \mu_{0} \cdot \mu_{\mathrm{r}}}},
$$

where
$f_{\mathrm{a}}[\mathrm{Hz}]$
- analysing frequency,
$\sigma\left[\Omega^{-1} \mathrm{~m}^{-1}\right]$
- specific conductivity,
$\mu_{0}[\mathrm{Vs} / \mathrm{Am}]$
$\mu_{\mathrm{r}}[-]$
- absolute permeability,
- relative permeability.

The changes of electric conductivity $\sigma$ and relative permeability $\mu_{\mathrm{r}}$, with reference to different tempering temperatures for steel $\mathrm{C} 45 \mathrm{E}$, which is the object of our study, are given in Table 3.

The data indicate that with the specimen having a tempering temperature $T_{\mathrm{t} 3}$ of $700{ }^{\circ} \mathrm{C}\left(\sigma=4.10^{6}\right.$ $\left.\Omega^{-1} \mathrm{~m}^{-1}\right)$ there is a considerably higher specific conductivity in the harder specimen material tempered at a temperature $T_{\mathrm{t} 1}$ of $220{ }^{\circ} \mathrm{C}\left(\sigma=1.5 .10^{6} \Omega^{-1} \mathrm{~m}^{-1}\right)$. A comparison of the values measured shows that the specific conductivity with a harder specimen increases by $166 \%$. A comparison of the relative permeability $\mu_{\mathrm{r}}$, however, shows that it increases with a soft specimen by $107 \%$. With increases in the electric conductivity and relative permeability of the material concerned, the magnetizing conditions will change too since softer materials will magnetise faster and the state of magnetic saturation will be attained faster as well.

The changes of the electric conductivity and relative permeability affect the degree of attenuation of the Barkhausen emission through the material depth, which affects the depth of sensing of the micro-magnetic changes. In addition to electric conductivity and relative permeability, the degree of attenuation of the Barkhausen emission through the material depth is affected also by the analysing frequency $f_{\mathrm{a}}$. In Table 4 measurement depths for five different analysing frequencies calculated using equation (1) are given.

Table 3: Electric conductivity and relative permeability of heat-treated specimens made of steel C45E.

\begin{tabular}{|c|c|c|}
\hline QUENCHED AND & ELECTRIC & PERMEABILITY \\
TEMPERED STEEL & CONDUCTIVITY & \\
$\mathbf{T}_{\mathbf{A}}=\mathbf{8 6 0} 0^{\circ} \mathbf{C}$ & $\sigma\left[\Omega^{-1} \mathbf{m}^{-1}\right]$ & $\mu_{\mathrm{r}}[-]$ \\
\hline $\mathrm{T}_{\mathrm{t} 1}=220^{\circ} \mathrm{C}$ & $1,5.10^{6}$ & 254 \\
\hline $\mathrm{T}_{\mathrm{t} 3}=700^{\circ} \mathrm{C}$ & $4.10^{6}$ & 525 \\
\hline
\end{tabular}

Table 4: Depth of Barkhausen noise captured as a function of analysing frequency $f_{\mathrm{a}}$.

\begin{tabular}{|c|c|c|}
\hline $\begin{array}{c}\text { ANALYSING } \\
\text { FREQUENCY } \\
\mathbf{f}_{\mathbf{a}}[\mathrm{kHz}]\end{array}$ & $\begin{array}{c}\text { SENSING DEPTH } \\
\mathrm{T}_{\mathrm{A}}=860^{\circ} \mathrm{C}, \mathrm{T}_{\mathrm{t} 1}=220^{\circ} \mathrm{C} \\
\sigma=1,5.10^{6}\left[\Omega^{-1} \mathrm{~m}^{-1}\right], \mu_{\mathrm{r}}=254 \\
\delta[\mu \mathrm{m}]\end{array}$ & $\begin{array}{c}\text { SENSING DEPTH } \\
\mathrm{T}_{\mathrm{A}}=\mathbf{8 6 0}{ }^{\circ} \mathrm{C}, \mathrm{T}_{\mathrm{t}}=700^{\circ} \mathrm{C} \\
\sigma=4.10^{6}\left[\Omega^{-1} \mathrm{~m}^{-1}\right], \mu_{\mathrm{r}}=525 \\
\delta[\mu \mathrm{m}]\end{array}$ \\
\hline 1 & 770 & 320 \\
\hline 20 & 350 & 150 \\
\hline 40 & 210 & 110 \\
\hline 100 & 105 & 70 \\
\hline 200 & 70 & 50 \\
\hline
\end{tabular}




\subsection{Determination of residual stresses}

In order to test the efficiency of prediction of residual stresses in the material on the basis of the magnetic Barkhausen noise a comparison of the measurement of residual stresses with the destructive relaxation method based on the continuous electrochemical removal was made. The residual stresses were first determined using the non-destructive micro-magnetic method, and then with the relaxation method using always the same specimens. The destructive relaxation method is a verified and efficient method; therefore, the results obtained for residual stresses were used to assess the efficiency of the micro-magnetic method in measuring the residual stresses.

Before starting the measurement of residual stresses for comparison's sake it was decided to first check the variation of residual stresses after heat treatment without subsequent grinding. This sequence was decided upon so that in the comparative measurement of residual stresses occurring after heat treatment and plane-surface grinding more accurate analyses of the influences exerted by each of the heat-treatment processes on the final magnitude of the residual internal stresses might be made.

The measurement of residual stresses after heat treatment was carried out using only the method of continuous electrochemical removal. The residual-stress variation after heat treatment is shown in Fig. 5.

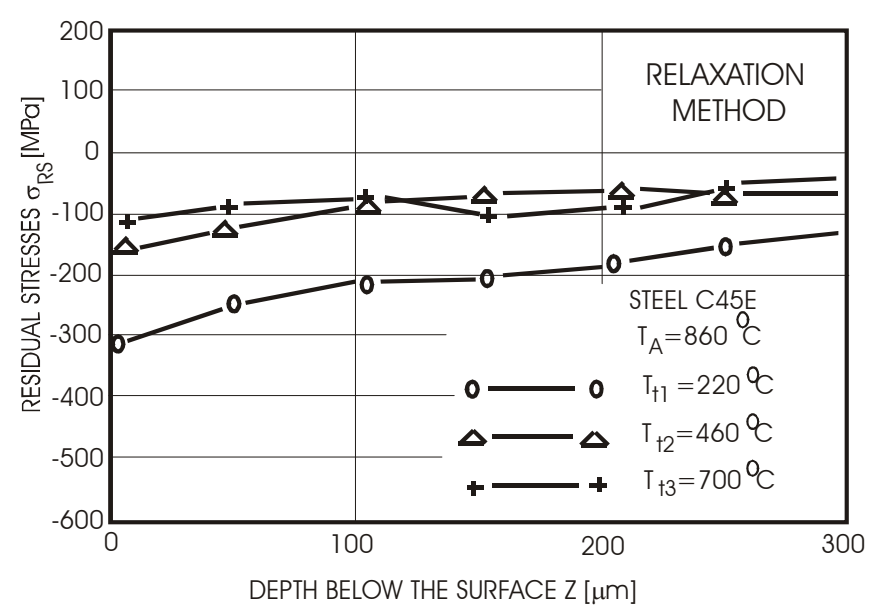

Fig. 5: Residual-stress variation in heat-treated specimens determined with relaxation method.

The tempered specimens with a temperature $T_{\mathrm{t} 1}$ of $220{ }^{0} \mathrm{C}$ show a microstructure of fine cubic martensite with an average value of $-300 \mathrm{MPa}$ at the surface. Compressive residual stresses were found through the entire specimen depth amounting to $300 \mu \mathrm{m}$. At the specimens with a higher high-tempering temperature $\left(T_{\mathrm{t} 2}=460{ }^{\circ} \mathrm{C}\right)$ a fine microstructure with fine feathers of cementite in the ferrite matrix and a lower value of residual stresses, i.e. -180 $\mathrm{MPa}$, was obtained. With higher high-tempering temperatures $\left(T_{\mathrm{t} 3}=700{ }^{0} \mathrm{C}\right)$ the specimens showed a microstructure of fine pearlite with coagulated cementite in the ferrite matrix and compressive residual stress of only $-110 \mathrm{MPa}$ was obtained at the surface.

After heat treatment the same specimens were plane-surface ground with the same type of grinder and under the same grinding conditions. The size and variation of the residual internal stresses after grinding were affected by the loading force $\mathrm{F}$ acting on the grinding grains, which depended on the material strength and the grinding parameters. The size by the loading force $F$ affects the wear or destruction of grinding grains, and thus the quality of the surface treated. Consequently, it affects also the variation of residual stresses.

Figure 6 shows two through-thickness profiles of residual stresses. The first profile shows the variation of residual stresses determined with the relaxation method, and the second one their variation determined with the micro-magnetic method. The results obtained show that the 
residual-stress profiles determined by either of the methods are in good agreement from the surface to the depth. The individual measurements of the residual stresses are represented by the calculated mean values of five measurements of residual stresses, i.e. five repetitions at the specimens treated in the same way. For both methods of measurement of the residual stresses the dissipation of results of five repetitions of measurement at individual depths was shown too. The difference among the individual mean values of the residual stresses obtained with the two methods amounted on the average to $5 \%$ to $15 \%$. Statistical tests showed that the differences among the individual measurements of the residual stresses were within the limits of confidence and as such were not significant ones.

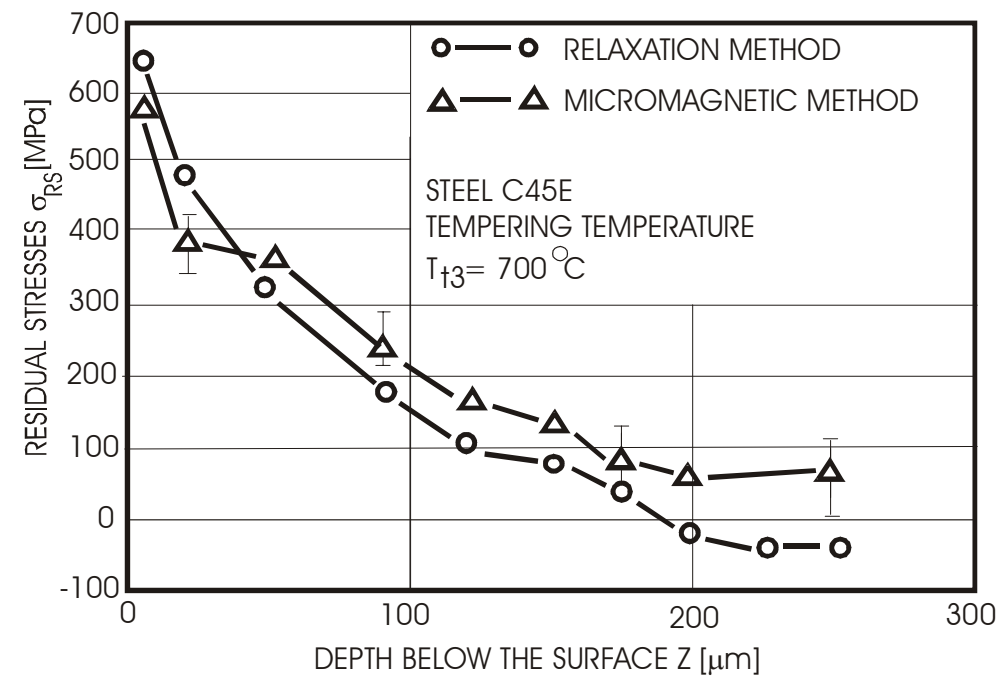

Fig. 6: Residual stresses after heat treatment and grinding determined with relaxation and micro-magnetic methods $\left(T_{\mathrm{t} 3}=700{ }^{\circ} \mathrm{C}\right)$.

The highest tensile residual stresses were obtained with the specimens heat-treated at the highest temperatures. A relevant cause of this may be heat treatment since at the specimens tempered after quenching at the highest temperatures, the lowest compressive residual stresses were obtained, and vice versa. The final magnitude of the residual stresses is affected by planesurface grinding, which due to the effect of super-positioning of both treatments provides the final residual stress.

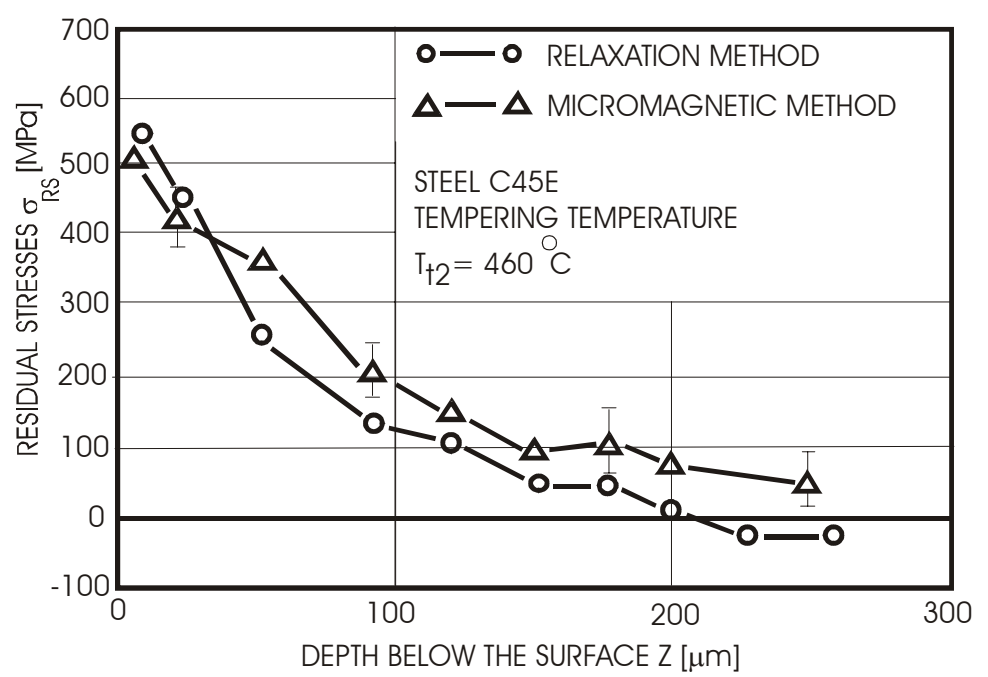

Fig. 7: Residual stresses after heat treatment and grinding determined with relaxation and micro-magnetic methods $\left(T_{\mathrm{t} 2}=460{ }^{\circ} \mathrm{C}\right)$. 


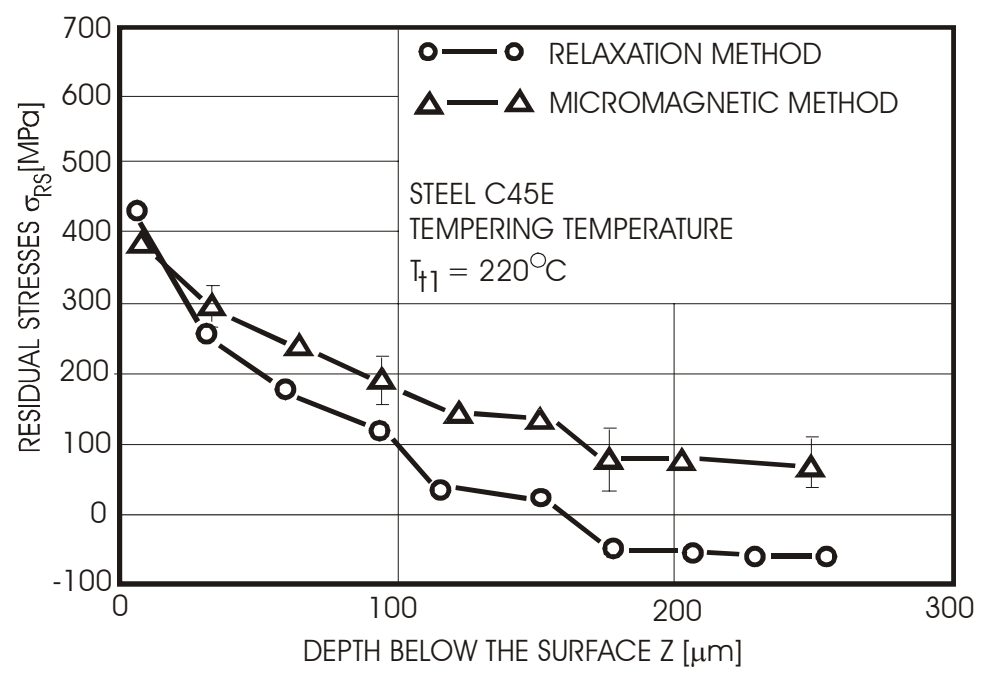

Fig. 8: Residual stresses after heat treatment and grinding determined with relaxation and micro-magnetic methods $\left(T_{\mathrm{t} 1}=220^{\circ} \mathrm{C}\right)$.

Similar results obtained are shown in Figs. 7 and 8. At the specimens the lower temperatures of high tempering after quenching produced a steeper gradient of compressive residual stresses both at the surface and in a greater depth. With both methods this resulted in lower final residual stresses after plane-surface grinding.

\section{Conclusions}

The determination of residual stresses using the micro-magnetic method based on the Barkhausen noise is related to the induced voltage measured in the measuring coil and to the choice of a suitable estimator (characteristics) permitting a comparative determination of the magnitude of residual stresses from the calibration curve. The residual stresses determined in this way were verified using the relaxation method based on the continuous electrochemical removal. A comparison of the results obtained in the measurement of residual stresses using the two methods showed that the differences at the individual depths varied between $5 \%$ and $15 \%$ with regard to the stress measured using the relaxation method. The statistical analysis showed that among the individual through-depth measurements of residual stresses there were no significant differences, which indicated a very good agreement of the measurements carried out using the two methods.

It is estimated that the relaxation method is more reliable for the determination of residual stresses than the micro-magnetic method since, in the first phase, it is based on the measurement of deformations, which are then transformed back to residual stresses by means of relevant algorithms. With the micro-magnetic method the through-depth precision of measurement slightly reduces since through-depth attenuation of the micro-magnetic noise is presumed.

\section{References}

[1] Degner W., Lauterlein T.: The Determination of Microhardness and Residual Stress of Machined Ferromagnetic Components by Using the Barkhausen Effect, Annals of the CIRP, Vol. 29, No. 1, $1980403-408$. 
[2] Yamada H., Kishimoto S., Isoh M., Takenaka Y.: Stress Analysis with Magnetic Anisotropy Sensor and its Application, Proceedings ob 11th WCNDT, Vol. 1, Las Vegas 1985, 607-614.

[3] Langman R.: Measurement of Stress by Magnetic Method, 4th European NDT Conference, London 1987, 65-70.

[4] Theiner W.A., Deimel P.: Non-destructive Testing of Welds with 3MA-Analyzer, Nuclear Engineering and Design, Vol. 102,1987, 257-264.

[5] Theiner W.A. Altpeter I.: Determination of Residual Stresses Using Micromagnetic Parameters, New Procedure in Nondestructive Testing (Proceedings) Ed.: P. Höller, Springer Verlag 1990.

[6] Desvaux S., Gualandri J., 2002, Stress Analisis on Bearing Raceway by Barkhausen Noise, Material Science Forum, Trans Tech Publications, 893-898.

[7] Grum, J., Žerovnik, P., 2002, Assessment of a Shot-peened Surface with the Micromagnetic Method, 32th International Conference and NDT Technique ExpositionDefectoscopy Liberec, 63-72.

[8] Suominen L., Tiitto K.: Use of X-ray Diffraction and Barkhausen Noise for the Evaluation of Stresses in Shot Peening, Proc. Of 4 the Intrn. Conf. On Residual Stresses, Baltimore, USA, 1994, 443-448.

[9] Suominen L., Wojtas A.: A Comparative Study of Barkhausen Noise and x-ray Diffraction Measurements from Ground Ferrite Steel Samples, 4. European Conference on Residual Stresses, Cluny, 1996, 1-7. 